\title{
Reduction of the Battery Capacity of Hybrid Electric Vehicle with the Help of Electrically Assisted Turbocharger
}

\author{
Milen Mihaylov ${ }^{1 *}$, Ivaylo Stoyanov ${ }^{2}$, and Teodor Iliev² \\ ${ }^{1}$ BorgWarner Turbo Systems, GmbH, Kirchheimbolanden, Germany \\ ${ }^{2}$ University of Ruse "Angel Kanchev”, 7017 Ruse, Bulgaria
}

\begin{abstract}
In this manuscript, the reduction of the battery capacity of a hybrid electric vehicle with the help of electrically assisted turbochargers was analyzed. Using the battery for vehicle propulsion and the options for its recharging, it could be concluded, that the most efficient way would be to use the battery energy for boosting mainly through eTurboTM and recharge the battery mainly with the traction motor in regenerative braking. Based on both steady-state and transient analysis it is clear, that for having the same dynamic HEV performance, the boosting with propulsion through ICE requires significantly less energy from the battery compared to the boosting through the traction motor. Therefore using the eTurboTM as boosting device can lead to reduce the battery capacity and reduce fuel consumption and emission of the vehicle.
\end{abstract}

\section{Introduction}

Hybrid Electric Vehicles (HEV) are getting more and more popular as an alternative to the classic vehicle powertrains with a standard Internal Combustion Engine (ICE). There are two main reasons for this trend. The main reason is the reduction of $\mathrm{CO}_{2}$, which is supposed to be the main driver for the Earth's global warming. The second reason is the superior driving performance of the HEV in terms of faster vehicle acceleration, which is known as a "Fun to Drive". This is possible because the HEV powertrains combine two driving systems - ICE + Electrical Driving System (EDS). The energy source for EDS is a battery. The battery is one of the most innovative and expensive parts of the HEV powertrain and its capacity is essential for its cost and weight.

Hybrid vehicles allow many functionalities such as recuperation, starter-generator torque support, etc. [2]. In [3], a hybrid meta-heuristic algorithm for gear optimization based on certain criteria is proposed.

The modern ICEs are equipped with a turbocharger, which allows increasing their power density and reduction of fuel consumption. The consequence of the reduced fuel consumption is reduced $\mathrm{CO}_{2}$ emissions $[4,5,6]$. Using a turbocharged engine as the main energy source of HEV powertrains allows using an Electrically Assisted Turbocharger - the so-called eTurbo ${ }^{\mathrm{TM}}$ - one of the most innovative products of BorgWarner. The eTurbo ${ }^{\mathrm{TM}}$

\footnotetext{
* Corresponding author: milenmihaylov@yahoo.com
} 
incorporates three machines fitted on a common shaft - the two turbo machines compressor and turbine, which are the main part of the classical turbocharger, and additionally one electric machine. The electric machine is the innovative part of the eTurbo ${ }^{\mathrm{TM}}$.

This paper shows that:

$>$ HEV with ICE boosted only with eTurbo $^{\mathrm{TM}}$ can offer the same Fun to Drive with lower battery capacity, compared to HEV with ICE boosted with classical turbocharger (without eTurbo ${ }^{\mathrm{TM}}$ ) + traction electric motor.

$>$ If having the same battery capacity HEV with ICE boosted with eTurbo ${ }^{\mathrm{TM}}+$ traction electric motor will have the same Fun to Drive + lower fuel consumption and therefore lower $\mathrm{CO}_{2}$ emissions.

\section{Boosting Options inside HEV Powertrains}

Depending on the way how the battery energy is used for boosting the HEV powertrains there are three options:

$>$ boosting through the eTurbo ${ }^{\mathrm{TM}}$ - the battery boosts the powertrain through eTurbo $^{\mathrm{TM}}$ and ICE (Fig. 1, A)

$>$ boosting through the traction motor - the battery boosts the powertrain through the traction electric motor (Fig. 1, B)

$>$ boosting through both eTurbo ${ }^{\mathrm{TM}}+$ traction motor - powertrain is boosted from both eTurbo $^{\mathrm{TM}}$ and traction motor (Fig. 1,C).

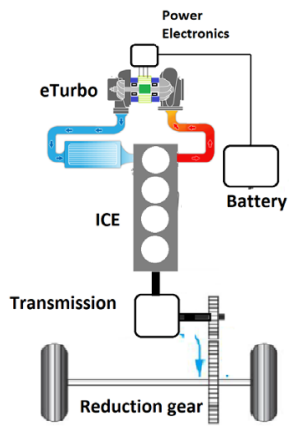

A)

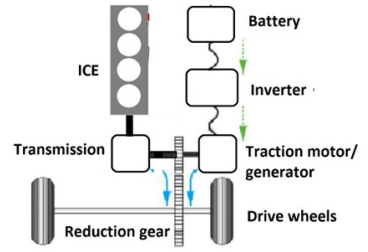

B)

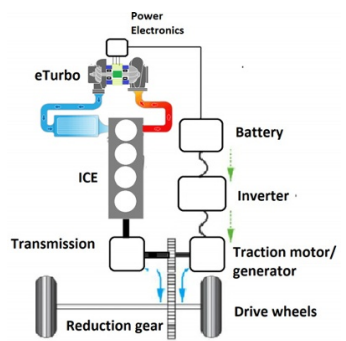

C)

Fig. 1. eTurbo boosting (A), EDS boosting (B), eTurbo + EDS boosting (C) [9]

The eTurbo ${ }^{\mathrm{TM}}$ boosting can be classified as indirect boosting, because first the ICE is boosted with the help of an additional boosting system and then the ICE boosts the HEV powertrain.

The traction motor boosting could be classified as direct boosting in the mild and power assist HEVs, because in these architectures the function of the traction motor is to support the ICE. The traction motor itself cannot power the vehicle alone. Therefore it has assisted or boosting function.

\subsection{Boosting through the eTurboTM}

As a part of the HEV powertrain, the ICE is always the main power source. Considering the standard vehicle powertrains, where ICE is the only power source, the term "boosting" is used for those ICEs, which have a system for forced air induction, commonly known as an air charging system, or just charging system. The charging system ensures engine power- 
boosting function by supplying pressurized air with low temperature into the engine cylinder during the piston induction stroke. The high pressure and low temperature mean higher air density, which results in increased cycle air mass. More air means, that more fuel can be burned. More fuel means higher power from the same cylinder displacement.

Apart from the increased engine power density, some types of charging systems are offering additional side benefits like improved engine efficiency and reduced tailpipe emissions.

There are many types of charging systems used in the ICEs. The most common and popular one is the charging/boosting system with Exhaust Gas Turbocharger (EGT), known as Turbocharger or simply Turbo.

BorgWarner is a leading turbocharger supplier in the automotive market with more than $50 \%$ market share.

The term "turbo" comes from the fact, that the EGT incorporates turbomachines for accomplishing its boosting function. The term "Exhaust Gas" means, that the energy for the boosting is extracted from the engine exhaust, leaving the cylinder during the piston exhaust stroke.

\subsubsection{Principal of turbocharging without electrical assistance (standard)}

The principle of turbocharging is shown in Fig. 2.

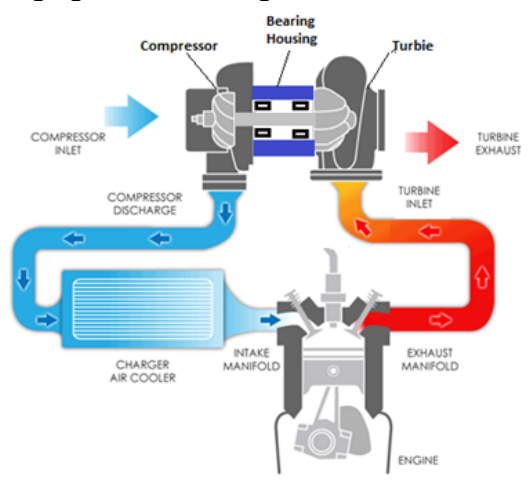

Fig. 2. Principal of turbocharging

The turbocharger is a device, which incorporates two machines - compressor and turbine (Fig. 2). They are connected to a common shaft. The shaft is supported on a bearing system (sliding or rolling bearing), accommodated in the bearing housing between the compressor and the turbine.

From the engine exhaust manifold, connected to the turbine inlet, the exhaust gas flows from the engine cylinder to the turbine during the piston exhaust stroke. A turbine is a machine that converts part of the exhaust gas enthalpy into the mechanical power of the common shaft. The shaft transmits the mechanical power to the compressor. The compressor converts the mechanical power into enthalpy of the fresh air. As a result the pressure and temperature of the air rise. The compressor outlet is connected to the charge air cooler device, where the pressurized air is cooled down at constant pressure, before entering the engine cylinder during the piston induction stroke. The pressurized air with the lower temperature inside the cylinder has a higher density and therefore bigger air mass is trapped, compared to the case of a naturally aspirated engine (engine without a turbocharger). With more air, more fuel can be burned and therefore higher engine power 
for the same engine displacement is achieved. Or if the engine displacement is reduced, with the help of the turbocharger a smaller engine can have the same power output, compared to a bigger engine without turbocharging. This is the so-called engine downsizing principle. The smaller engine has lower friction losses and can work more efficiently with less fuel consumption and fewer tailpipe emissions. The smaller engine is also cheaper and lighter, which is another advantage for the vehicle.

The main disadvantage of turbocharged engines is the slower response to the engine load. This means, that when the driver pushes the accelerator pedal the engine torque/power rise is delayed, and hence the vehicle acceleration has a certain delay. The reason for this is, that a certain time is needed for the turbine to collect exhaust gas and to convert its enthalpy to boost pressure in the intake manifold through the compressor. A certain time is necessary also the entire piping volume and charge air cooler between the compressor exist and engine cylinder to be filled to higher pressure, due to the compressibility of the air. And last but not least, the rotating components of the turbocharger - the compressor wheel and the turbine wheel have mass inertia, and to accelerate to higher speed, additional energy is necessary.

The vehicle acceleration demand appears more often at lower vehicle speed and lower engine speed when there is not a sufficient amount of exhaust gas for the turbine. To create sufficient power, the turbine is usually sized smaller, i.e. with less flow capacity. This helps for faster acceleration, but it is a drawback when the engine operates at higher speeds and loads. The turbine cannot permeate the entire exhaust flow amount, or if it permeates it the turbo shaft speed will rise above the mechanical limits, which will destroy the weakest rotating component. Additionally, the boost pressure control and engine load cannot be controlled. Therefore a protecting/regulating device is needed, which can be a turbine bypass valve, which releases part of the exhaust flow directly from the turbine inlet to the turbine outlet. This solves the engine control and prevents the turbocharger from overspeeding, but leads on the other hand to increased pressure inside the engine cylinder, which is not favorable for the engine combustion and gas exchange process and causes increased fuel consumption.

If the turbine is sized for higher flow capacity, then it will not create such high pressure in the engine cylinder, but then the vehicle acceleration and the "Fun to drive" will suffer at lower speeds. Therefore the turbine sizing is always a compromise.

\subsubsection{Principal of turbocharging with electrical assistance (eTurboTM)}

There are some ways how to minimize this compromise. A very popular and widely spread one is using the Variable Geometry Turbine (VTG), which is since decades in serial production. Or using multistage charging systems with more than one turbocharger connected in series or parallel and some others.

But in the case of HEV, there is accumulated electric energy stored in a battery. This energy could be used in several ways to boost the HEV. This is how the idea for electrically assisted turbochargers appears.

To the shaft of the classical turbocharger, (Fig. 3A, Fig.2), which has two turbomachines on a common shaft is fitted a third electric machine (Fig. 3B). There are several design concepts, but the most common one is with an electric machine fitted inside the bearing housing. This machine can work as an electric motor adding mechanical power to the shaft to support the turbine for driving the compressor, or to work as a generator, consuming mechanical energy from, when the turbine has excess power. In electric motor mode, electrical energy is provided to the motor from the battery of the HEV. In generator mode, the electric energy could be used directly for the traction electric motor(s) of the $\mathrm{HEV}$ or for recharging the battery. 
Having an additional power device on the shaft as an electric motor, the compressor has additional support for acceleration and the turbine can be sized for higher flow capacity, which is beneficial for the engine combustion and gas exchange processes at higher engine speeds and loads.

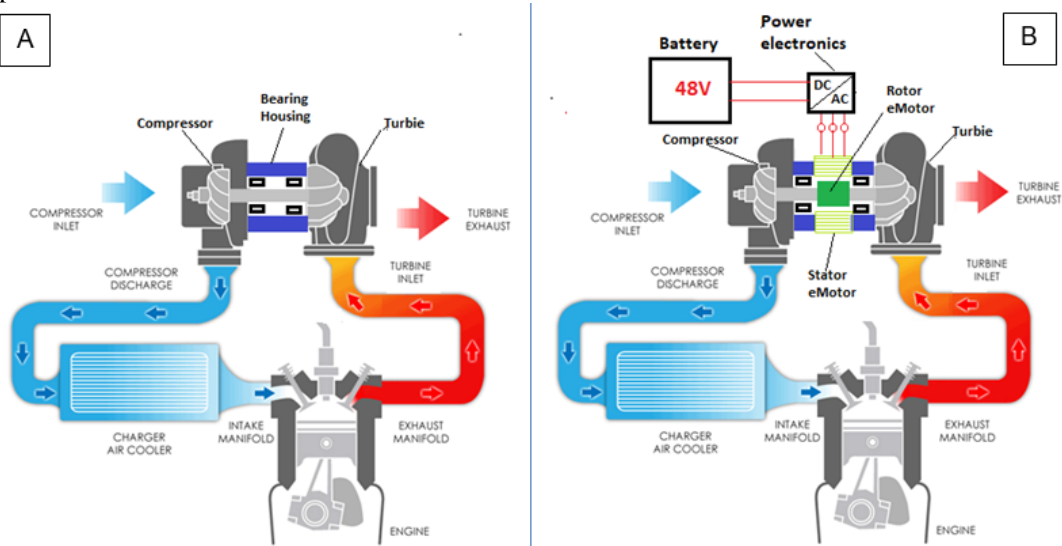

Fig. 3. Principal of turbocharging without (A) and with (B) electrical assistance

This is how the eTurbo ${ }^{\mathrm{TM}}$ can use the electric energy from the battery to generate an additional boost on ICE, which boosts the HEV powertrain for better vehicle dynamic performance and faster acceleration, and superior "Fun to drive".

This is an indirect way of using the battery to boost the HEV powertrain. The battery energy is used from the Turbo ${ }^{\mathrm{TM}}$ motor to pressurize air through the compressor. The compressor boosts the ICE and the ICE then boosts the HEV powertrain. There are several energy transformation processes involved.

Having an additional power device on the shaft as a generator, the excess turbine power at higher engine speeds and loads could be harvested and utilized to generate electric energy for the needs of traction motor or for recharging the battery, instead of fully wasting it through bypass valve as it happens in case of the classic turbocharger.

The electric machine of eTurbo $^{\mathrm{TM}}$ is a Permanent Magnet Synchronous Machine (PMSM) with permanent magnets inside the rotor.

A common view of BorgWarner eTurbo ${ }^{\mathrm{TM}}$ product with some product features and specifications is shown in Fig. 4 [7].
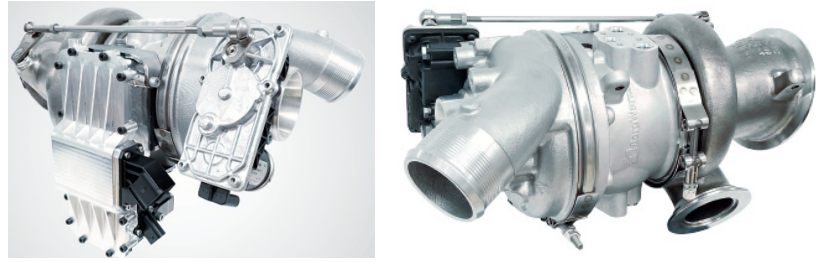

Fig. 4. A common view of BorgWarner eTurbo product [7]:

\section{Product Features}

Full performance $48 \mathrm{~V}$ architecture and $\mathrm{HV} \_2 \mathrm{~B}$ and HV 3 compliant high voltage architectures; Integrated and semi-integrated power electronics options including using engine coolant.

\section{Specifications}

Platform eTurbo - 48V 3kW ... 17kW; 400/ $800 \mathrm{~V} 6 \ldots 34 \mathrm{~kW}$ peak. Versions: eB40. eB50. eB60 and eB80 samples with alternate motor length and voltage classes for each frame size 


\subsection{Boosting through traction motor(s)}

It was shown, that the eTurbo ${ }^{\mathrm{TM}}$ is an indirect way of using the battery for HEV powertrain boosting while boosting through traction motor is a direct way. The battery energy is used to drive the traction electric motor(s) with only one energy conversion process from electrical to mechanical power.

Therefore one can assume that the boosting through the traction motor is more efficient and would need less energy from the battery and lower battery capacity for the same vehicle performance.

Jaguar Land Rover Limited in collaboration with BorgWarner Turbo Systems and MAHLE Powertrain Limited have performed an engine dyno test with an engine from Jaguar Land Rover engine equipped with BorgWarner eTurbo ${ }^{\mathrm{TM}}$ product. Based on the collected test data there is a possibility to calculate comparatively:

$>$ what is the electric energy consumed from the eTurbo ${ }^{\mathrm{TM}}$ electric motor to achieve certain performance only through eTurbo $^{\mathrm{TM}}$ boosting;

$>$ what would be the electric energy consumed from the traction motor to achieve the same performance through traction motor boosting.

\section{Engine test data}

\subsection{Engine test data at steady-state full load}

The presented diagrams are obtained experimentally. The 2L Turbocharged gasoline engine of automotive manufacture Jaguar Land Rover was equipped with electrically assisted turbocharger designed, manufactured and supplied from the turbocharger supplier BorgWarner Turbo Systems. The engine test was performed at the testing facilities of the company MAHLE Powertrain. The steady state and the transient testing procedure are standard testing procedures for testing of turbocharged Internal Combustion Engines. That is why their test procedure were not in detail described. The terms "steady state full load" and "transient" with the given engine speeds describes both test fully. The main focus was to analyze the test data measured using a standard full load and transient test procedures in comparative way. In Fig. 5 is shown the ICE full load torque curve and the eTurbo ${ }^{\mathrm{TM}}$ motor electrical power consumption. The blue lines are with deactivated eTurbo $^{\mathrm{TM}}$ and the red lines are with activated $\mathrm{eTurbo}^{\mathrm{TM}}$. Let's consider the second operation point at an engine speed of $1200 \mathrm{rpm}$.
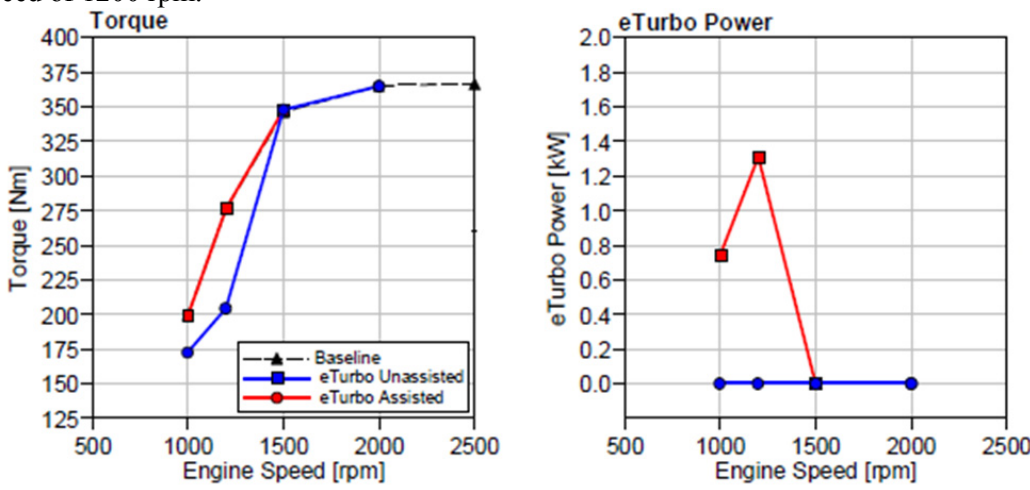

Fig. 5. Engine torque and eTurbo motor power [8] 
Based on the ICE torque and ICE speed, ICE power is calculated for both cases with activated and deactivated eTurbo ${ }^{\mathrm{TM}}$. (Table 1).

Table 1. Calculated ICE speed and power.

\begin{tabular}{|c|c|c|c|c|}
\cline { 2 - 5 } \multicolumn{1}{c|}{} & ICE speed & ICE Torque & ICE Power & eTurbo power \\
\cline { 2 - 5 } \multicolumn{1}{c|}{} & $\mathrm{rpm}$ & $\mathrm{Nm}$ & $\mathrm{kW}$ & $\mathrm{kW}$ \\
\hline eTurbo ON & 1200 & 275 & 34.56 & 1.3 \\
\hline eTurbo OFF & 1200 & 205 & 25.76 & 0 \\
\hline
\end{tabular}

When the eTurbo ${ }^{\mathrm{TM}}$ is deactivated the boost pressure for the engine is created only from the energy of the exhaust gas through the turbine and compressor. The motor of the eTurbo $^{\mathrm{TM}}$ is not active and does not generate shaft power. This corresponds to classical turbocharger operation without electrical assistance (Fig 3A). The boost pressure, which the turbocharger can create is enough for the engine to achieve $205 \mathrm{Nm}$ or $25.76 \mathrm{~kW}$ of power.

When the eTurbo ${ }^{\mathrm{TM}}$ motor is activated with electric power from the battery, it supplies additional $1.3 \mathrm{~kW}$ power to the turbocharger shaft. With this additional power, the turbo speed increases and the compressor is capable to create higher boost pressure for the ICE. As a result, the torque of ICE rises from $205 \mathrm{Nm}$ to $275 \mathrm{Nm}$ (70 Nm torque rise) and the ICE power rises from $25.76 \mathrm{~kW}$ to $34.56 \mathrm{~kW}(8.8 \mathrm{~kW}$ power rise). In percentage, the engine power rises by $34.1 \%$. In other words, for battery power of $1.3 \mathrm{~kW}$, ICE provides $8.8 \mathrm{~kW}$ additional power for the vehicle.

In case that the vehicle is equipped $48 \mathrm{~V} 50$ Ah battery, this means accumulated energy in the battery is $2.4 \mathrm{kWh}$. Recommended battery Depth of Discharge (DoD) is $70 \%$. This means, that the available energy for the eTurbo motor will be $2.4 \mathrm{kWhx} 70 / 100=1.68 \mathrm{kWh}$. At a power consumption of $1.3 \mathrm{~kW}$, eTurbo can work and boost the vehicle for approximately 1 hour and 18 minutes.

The task we set is, if the boosting function of the vehicle would be delivered only from the traction motor (Fig. 1B), to determine how much power would the traction motor need to boost the HEV powertrain with the same magnitude of $8.8 \mathrm{~kW}$.

The answer is easy and clear. The additional $8.8 \mathrm{~kW}$ instead of the ICE has to be delivered from the traction motor.

For the same $48 \mathrm{~V}, 50 \mathrm{Ah}(2.4 \mathrm{kWh})$ battery discharged to the same $70 \% \mathrm{DoD}$ the available energy for the traction motor will be theoretically the same $1.68 \mathrm{kWh}$. To deliver $8.8 \mathrm{kWh}$ shaft power, assuming $95 \%$ traction motor efficiency and $97 \%$ power electronics efficiency it would consume $8.8 / 0.95 / 0.97=9.55 \mathrm{~kW}$. With an energy of $1.68 \mathrm{kWh}$ and 9.55 $\mathrm{kW}$ consumption, the battery would last approximately $11 \mathrm{~min}$. But it would be less than 11 min, because with $9.55 \mathrm{~kW}$ discharging power the traction motor withdraws the battery with about 7.35 times higher current $(9.55 / 1.3=7.35)$ compared to the eTurbo ${ }^{\mathrm{TM}}$ motor, discharging the battery with $1.3 \mathrm{~kW}$. At this higher current, the battery internal losses would be higher and the available energy to $\mathrm{DoD}=70 \%$ would be less than $1.68 \mathrm{kWh}$.

\subsection{Engine test data at unsteady (transient) conditions}

In Fig. 6A is shown the ICE transient performance, which represents the engine torque rise over time. For the vehicle, this means the acceleration process, when the driver steps on the gas pedal. The faster torque rise means faster vehicle acceleration. Several curves are shown. Each of them represents the ICE torque rise rate for different eTurbo ${ }^{\mathrm{TM}}$ motor shaft torque limits, starting from $0.2 \mathrm{Nm}$ to $1.6 \mathrm{Nm}$.

Fig. $6 \mathrm{~B}$ is shown the correspondent eTurbo $^{\mathrm{TM}}$ motor electric power consumption. In Fig $6 \mathrm{C}$ with dotted line is shown the electric energy, which the eTurbo ${ }^{\mathrm{TM}}$ consumes for each torque limitation. This energy is the cumulative energy calculated as an integral of the data points from the eTurbo ${ }^{\mathrm{TM}}$ power curves in Fig. 6B. 
For the analysis here let's take the case of the maximum ICE torque rise rate, at eTurbo ${ }^{\mathrm{TM}}$ shaft torque limit of $1.6 \mathrm{Nm}$. This is the red curve for which transient time is $0.6 \mathrm{~s}$. This will be compared to the baseline, which is the grey dashed curve, where eTurbo ${ }^{\mathrm{TM}}$ is switched off.

The cumulative energy, which the vehicle equipped with this ICE needs to accelerate for $0.6 \mathrm{~s}$ (red acceleration curve on Fig. 6A with eTurbo ${ }^{\mathrm{TM}}$ shaft torque limit of $1.6 \mathrm{Nm}$ ), calculated as an integral over the acceleration time is $17.2 \mathrm{~kJ}=4.78 \mathrm{Wh}$. The eTurbo ${ }^{\mathrm{TM}}$ electric energy consumption from the battery is $6 \mathrm{~kJ}=1.67 \mathrm{Wh}$.

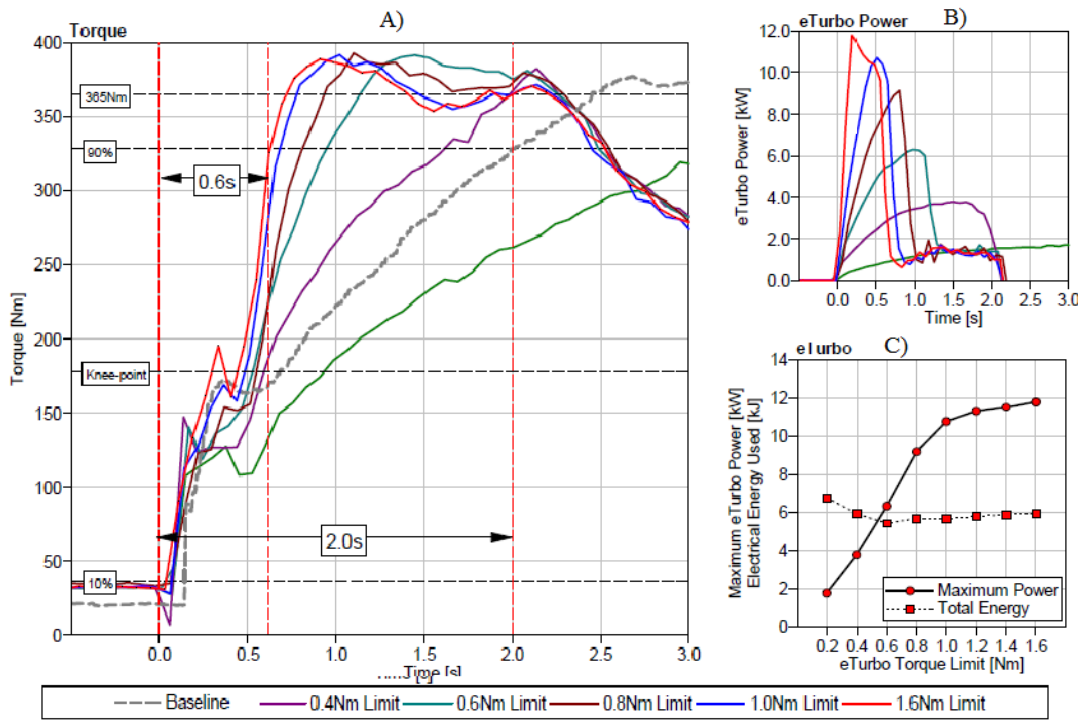

Fig. 6. Engine torque (A) and eTurboTM motor power (B) and cumulative eTurboTM energy (C) [8]

The cumulative energy, which the vehicle equipped with this ICE needed to accelerate for $2 \mathrm{~s}$ (Baseline grey dashed curve on Fig. $6 \mathrm{~A}$, the eTurbo ${ }^{\mathrm{TM}}$ is switched off), calculated as an integral over the acceleration time is $57.3 \mathrm{~kJ}=15.93 \mathrm{Wh}$. The eTurbo ${ }^{\mathrm{TM}}$ electric energy consumption from the battery is $0 \mathrm{Wh}$ (Table 2).

Table 1. Cumulative Energy for vehicle acceleration.

\begin{tabular}{|c|c|c|c|}
\cline { 2 - 4 } \multicolumn{1}{c|}{} & Acceleration time, $\mathrm{s}$ & $\begin{array}{c}\text { Cumulative Energy for } \\
\text { vehicle acceleration, } \mathrm{Wh}\end{array}$ & $\begin{array}{c}\text { eTurbo energy consumption, } \\
\text { Wh }\end{array}$ \\
\hline $\begin{array}{c}\text { eTurbo ON } \\
1.6 \mathrm{Nm} \text { limit }\end{array}$ & 0.6 & 4.78 & 1.66 \\
\hline eTurbo OFF & 2 & 15.93 & 0 \\
\hline
\end{tabular}

The eTurbo ${ }^{\mathrm{TM}}$ contributes to reducing the vehicle acceleration energy demand with 11.15 Wh from 15.93 to $4.78 \mathrm{Wh}$ for the expense of $1.66 \mathrm{Wh}$ energy consumed from the battery.

If a battery with the same capacity (48V 50Ah) is considered like for the steady-state calculations, the available energy for DoD of $70 \%$ is $1.68 \mathrm{kWh}$. With this energy amount, the eTurbo ${ }^{\mathrm{TM}}$ will support $1.68 /(1.66 / 1000)=1012$ vehicle acceleration events.

If the same vehicle acceleration in $0.6 \mathrm{~s}$ is not supported from the eTurbo ${ }^{\mathrm{TM}}$, but from traction electric motor the energy for 1 acceleration event will be $15.93 \mathrm{Wh}$. With 1.68 $\mathrm{kWh}$ of battery energy, the traction motor would support $1.68 /(15.93 / 1000)=106$ 
acceleration events, which is almost 10 times less compared to the acceleration support from eTurbo ${ }^{\mathrm{TM}}$.

\section{Options for recharging the battery of HEV}

Having electric machines on the board of HEV, they are used not only in motor mode to boost or drive the vehicle but also in generator mode. The generated electric energy can be used to recharger the battery, which is mandatory for the HEV architectures, which are not Plug-In. They have to be designed in the way that the battery is recharged without an additional external energy source. Usually, the battery recharging energy in non-plug-in HEVs comes from the utilization of the vehicle braking energy. The classical friction brakes convert the vehicle kinetic energy during the braking process into heat energy, which is dissipated in the environment. Using the traction motors in generator mode, allows part of the braking energy to be converted into electrical and recharge the battery.

The eTurbo ${ }^{\mathrm{TM}}$ electric machine can also work in generator mode and generate electric energy from the excess exhaust gas energy of the ICE. This is another source available in HEVs to generate electric energy, which could be harvested through eTurbo ${ }^{\mathrm{TM}}$.

The advantage of using the $\mathrm{eTurbo}^{\mathrm{TM}}$ to generate electric energy is that it can be directly used to power the traction motor instead of storing it in the battery. The advantage in this case, that the energy losses for charging and discharging the battery can be avoided. This leads to a reduction of the battery cycles and longer battery life. Of course, charging the battery is also an option, but a less efficient one. On the other hand, using the eTurbo ${ }^{\mathrm{TM}}$ in generator mode has some disadvantages for the ICE combustion and gas exchange processes, which was explained earlier. But there are certain ICE operation conditions where using the eTurbo in generator mode is beneficial for the entire powertrain energy balance.

The advantage of using the traction motor in generator mode during the vehicle braking process is that it does not have any negative influence on other components (like the $\mathrm{eTurbo}^{\mathrm{TM}}$ in generator mode has on ICE). The more energy harvested from the braking process the better. In general, the traction motor is capable to generate more energy from the braking, compared to the eTurbo ${ }^{\mathrm{TM}}$ from the exhaust gas. The disadvantage of generation with traction motor is that this process takes place only during vehicle braking and the generated energy has to be stored in the battery and cannot be directly used for vehicle propulsion, because during the braking the propulsion is simply not needed. Like this, the generated electrical energy from the traction motor and its later usage for vehicle propulsion has to go through battery charging and discharging cycle, which is related to energy losses in the battery and the power electronics. In case that the battery has reached its $100 \%$ state of charge, the braking energy cannot be converted into electricity for charging the battery.

\section{Conclusion}

Based on both steady-state and transient analysis it is clear, that for having the same dynamic HEV performance (the same "Fun to Drive"), the boosting with propulsion through ICE requires significantly less energy from the battery compared to the boosting through the traction motor. Therefore using the eTurbo ${ }^{\mathrm{TM}}$ as boosting device can be an option to:

$>$ reduce the battery capacity, which will have cost weight and packaging advantage for the vehicle

$>$ reduce fuel consumption and emission if keeping the same battery capacity 
Based on the analysis of the options for using the battery for vehicle propulsion and the options for its recharging, it could be concluded, that the most efficient way would be to use the battery energy for boosting mainly through eTurbo ${ }^{\mathrm{TM}}$ and recharge the battery mainly with the traction motor in regenerative braking. The most efficient way of utilizing the eTurbo ${ }^{\mathrm{TM}}$ generated electric energy is using it for direct vehicle propulsion instead of storing it in the battery and uses it later on.

\section{References}

1. X. Feihong, P. Griefnow, F. Tidau, et al., Electric torque assist and supercharging of a downsized gasoline engine in a $48 \mathrm{~V}$ mild-hybrid powertrain, Proceedings of the Institution of Mechanical Engineers, Part D: Journal of Automobile Engineering, November 3, (2020), pp. 1245-1255, DOI: 10.1177/0954407020968956

2. C. Wu, K. Song, S. Li, H. Xie, Impact of Electrically Assisted Turbocharger on the Intake Oxygen Concentration and Its Disturbance Rejection Control for a Heavy-duty Diesel Engine. Energies. 2019; 12(15):3014. DOI: 10.3390/en12153014

3. V. Kamboj, S. Saxena, K. Sandhu, Optimal Selection of Gear Ratio for Hybrid Electric Vehicles Using Modern Meta-Heuristics Search Algorithm, E3S Web Conf. 8701006 (2019), DOI: $10.1051 / \mathrm{e} 3 \mathrm{sconf} / 20198701006$

4. N. Connelly, D. George, A. Nix, and W. Generation and Analysis of Hybrid-Electric Vehicle Transmission Shift Schedules with a Torque Split Algorithm. Journal of Transportation Technologies, 10, 21-49, (2020) DOI: 10.4236/jtts.2020.101003

5. L. Wang, S. Wang, and Z. Song, Control Strategy and Performance Simulation Study on Extended Range Electric Vehicle, E3S Web Conf., 79 (2019) 03006, DOI: https://doi.org/10.1051/e3sconf/20197903006

6. A. Ekbote, M. Karvinkoppa, V. Bhojwani, and N. Patil, Comprehensive study on smart cooling techniques used for batteries, E3S Web Conf. 17001028 (2020), DOI: $10.1051 / \mathrm{e} 3$ sconf $/ 202017001028$

7. Electric Boosting Technologies - BorgWarner (https://www.borgwarner.com, 2021)

8. A. Cooper, M. Bassett, J. Hall, A. Harrington, et al., HyPACE - Hybrid Petrol Advance Combustion Engine - Advanced Boosting System for Extended Stoichiometric Operation and Improved Dynamic Response, (SAE Technical Paper 2019-01-0325, 2019), DOI: 10.4271/2019-01-0325.

9. H. Stanchev, Types of hybrid electric cars (HEV). Advantages and disadvantages, (in Bulgarian), University of Ruse (http://cdo.uni-ruse.bg, 2017) 